\title{
Relationship Between Chronic Stress and Heart Rate Over Time Modulated by Gender in a Cohort of Office Workers: Cross-Sectional Study Using Wearable Technologies
}

Alex Wilhelmus Jacobus van Kraaij ${ }^{1,2,3}$, MSc; Giuseppina Schiavone ${ }^{1,2}, \mathrm{PhD}$; Erika Lutin ${ }^{4,5}$, MSc; Stephan Claes ${ }^{6}$, Prof Dr; Chris Van Hoof ${ }^{1,2,4,5}$, Prof Dr

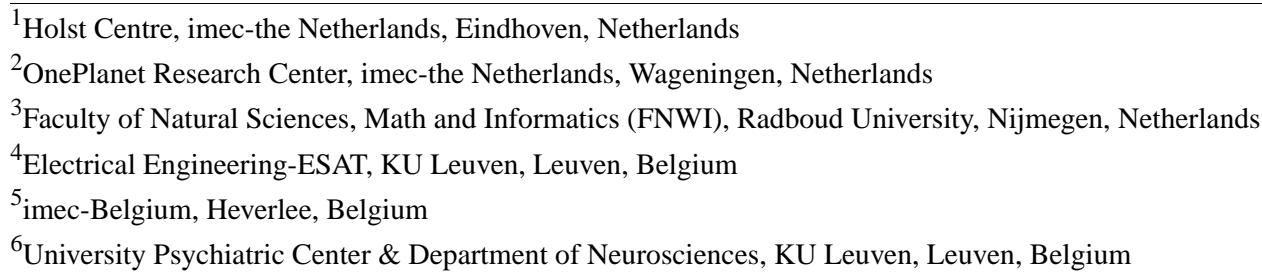

\section{Corresponding Author:}

Alex Wilhelmus Jacobus van Kraaij, MSc

OnePlanet Research Center

imec-the Netherlands

Bronland 10

Wageningen, $6708 \mathrm{WH}$

Netherlands

Phone: 31404020400

Email: alex.vankraaij@imec.nl

\section{Abstract}

Background: Chronic stress is increasing in prevalence and is associated with several physical and mental disorders. Although it is proven that acute stress changes physiology, much less is known about the relationship between physiology and long-term stress. Continuous measurement of vital signs in daily life and chronic stress detection algorithms could serve this purpose. For this, it is paramount to model the effects of chronic stress on human physiology and include other cofounders, such as demographics, enabling the enrichment of a population-wide approach with individual variations.

Objective: The main objectives of this study were to investigate the effect of chronic stress on heart rate (HR) over time while correcting for weekdays versus weekends and to test a possible modulation effect by gender and age in a healthy cohort.

Methods: Throughout 2016 and 2017, healthy employees of technology companies were asked to participate in a 5-day observation stress study. They were required to wear two wearables, of which one included an electrocardiogram sensor. The derived HR was averaged per hour and served as an output for a mixed design model including a trigonometric fit over time with four harmonics (periods of 24, 12,8, and 6 hours), gender, age, whether it was a workday or weekend day, and a chronic stress score derived from the Perceived Stress Scale (PSS) as predictors.

Results: The study included 328 subjects, of which 142 were female and 186 were male participants, with a mean age of 38.9 (SD 10.2) years and a mean PSS score of 13.7 (SD 6.0). As main effects, gender $\left(\chi_{1}^{2}=24.02, P<.001\right)$; the hour of the day $\left(\chi_{1}^{2}=73.22, P<.001\right)$; the circadian harmonic $\left(\chi_{2}^{2}=284.4, P<.001\right)$; and the harmonic over 12 hours $\left(\chi_{2}^{2}=242.1, P<.001\right)$, over 8 hours $\left(\chi_{2}^{2}=23.78, P<.001\right)$, and over 6 hours $\left(\chi_{2}^{2}=82.96, P<.001\right)$ had a significant effect on HR. Two three-way interaction effects were found. The interaction of age, whether it was a workday or weekend day, and the circadian harmonic over time were significantly correlated with $\mathrm{HR}\left(\chi_{2}^{2}=7.13, P=.03\right)$, as well as the interaction of gender, PSS score, and the circadian harmonic over time $\left(\chi_{2}^{2}=7.59, P=.02\right)$.

Conclusions: The results show a relationship between HR and the three-way interaction of chronic stress, gender, and the circadian harmonic. The modulation by gender might be related to evolution-based energy utilization strategies, as suggested in related literature studies. More research, including daily cortisol assessment, longer recordings, and a wider population, should 
be performed to confirm this interpretation. This would enable the development of more complete and personalized models of chronic stress.

(J Med Internet Res 2020;22(9):e18253) doi: 10.2196/18253

\section{KEYWORDS}

chronic stress; heart rate; circadian rhythm; gender; age; wearable device

\section{Introduction}

\section{Background}

The number of individuals having chronic stress and stress-related mental disorders, such as depression, is increasing globally [1]. While in most cases, the stress response of the human body protects the body in harmful environments, when stress occurs for a prolonged period, it can have several negative health effects [2]. As a matter of fact, chronic stress is known to increase the risk of developing a range of mental and physical disorders [3]. Examples of mental disorders are burnout, depression, and anxiety disorders, while related physical disorders include gastrointestinal disorders, obesity, diabetes, and heart diseases [3]. Moreover, chronic stress is often referred to as an economical problem. In 2018, a review was published on the costs of illness for work-related stress, suggesting that total costs per country could range from US \$221 million to US $\$ 187$ billion each year [4]. For these reasons, it is of critical importance to successfully monitor and manage chronic stress in the entire population, without losing individual-based focus as in current one-on-one psychotherapy.

As described by Kaplan [5], there are many challenges that researchers as well as doctors and therapists face to assess and monitor chronic stress levels in daily life. Although these challenges are already known for a long time, they have not been overcome. Stress questionnaires are the most common and convenient tools used for assessing chronic stress. Questionnaires, such as the Perceived Stress Scale (PSS) that is designed to assess the long-term stress effect (ie, stress over the last month), have been proven to have adequate reliability across different cohorts [6-8]. Nevertheless, they remain subjective measurements that are subject to recall errors and unable to capture the impact of stress on normal physiological functioning [9]. Over the past years, many algorithms and applications have been developed for acute stress detection based on physiological signals [10]. Predictors used are, for example, heart rate (HR), HR variability, skin conductance, and skin temperature [10-12]. Some algorithms can detect acute stress responses with high accuracy (>90\%) in controlled conditions $[11,12]$. Detection algorithms based on real-time monitoring of physiological parameters could improve the objectivity of stress detection, facilitate capturing early signs of chronic stress, and support stress management in clinical practice, functioning both as awareness and feedback tools for users and therapists.

Most of the efforts in this field have focused, so far, on acute stress detection algorithms, showing the difficulty of generalization and the importance of individual-based models $[13,14]$. Literature on complete physiological modeling of chronic stress in humans remains poor owing to the complexity and high cost of collecting longitudinal real-world data. This complexity needs to be addressed first by linking long-term physiology measurements to chronic stress. Van Uum et al [15] found elevated hair cortisol levels in patients with severe chronic pain and higher PSS scores. Using a repeated measurement design, Schulz et al [16] reported that the awakening salivary cortisol level should be considered a possible biological correlate of chronic stress, as it was found to be elevated in participants with higher chronic stress levels. Schulz et al also found a gender difference in their study, showing larger increases of morning salivary cortisol levels in women than in men. This gender difference in physiological responses to chronic and acute stress has also been investigated by Jones et al [17]. In this previous study, it was found that chronic stress, measured according to the PSS score, modulates both the cortisol stress response and the cardiovascular stress response differently for male and female individuals. Female individuals had a lower $\mathrm{HR}$ at rest for higher PSS scores, whereas among male individuals, this correlation was not found. However, male individuals did show a lower HR while in acute stress for higher PSS scores. This second correlation was not found among female individuals.

When studying effects on physiology over multiple days, the circadian rhythm is used to describe diurnal physiological fluctuations [18]. For example, Cho et al [19] developed a model for mood prediction in patients with mood disorders, using the properties of the cosine curve in HR as one of the predictors. Tsanas et al [20] also stressed the importance of the circadian rhythm in monitoring under free-living conditions. Morelli et al [21] described this circadian rhythm in HR as four harmonics with periods of $24,12,8$, and 6 hours. Their accurate approximation of the resting HR using these four harmonics makes this modeling suitable for mapping long-term effects on HR. Another important aspect to consider while studying effects on physiology over time is the weekday-weekend difference. In the study by Schlotz et al [22], it was shown that the cortisol response, often related to stress, is different for weekdays versus weekends. Chronic work overload and worrying was found to be related to this rise in cortisol after awakening on workdays, but not on weekend days. This effect was independent of gender. Pantzar et al [23] also found dissimilarities in stress patterns between weekend days and workdays when studying HR in response to stress. This difference was modulated by gender, and there was a smaller effect size by age [23].

By combining the approaches and findings from the studies described above in our study, we analyzed the long-term HR response to chronic stress and its bias for gender and age. Different from previous studies, we used wearable technologies to capture circadian variation of HR over multiple days. 


\section{Objectives of the Study}

The main objectives of this study were as follows:

- To investigate the effect of chronic stress on HR over time, while correcting for weekdays versus weekends. For this, chronic stress has been defined as long-term perceived stress.

- $\quad$ To test possible modulation effects by gender and/or age. All interaction effects of these predictors will be included.

The outcomes of this analysis could be integrated into novel computational models of chronic stress detection, according to vital signs collected daily, for example, using widely adopted fitness trackers.

\section{Methods}

\section{Recruitment}

This study is part of the Stress in Work Environment (SWEET) study conducted by imec, which has been described previously [13]. Participants were recruited via email in 11 technology-oriented companies and were all office workers. They were included if they were active employees at the time of the study. No other inclusion or exclusion criteria were applied. Participants did not receive any compensation for participating in the study apart from having a chance at winning a restaurant or travel voucher. Vital signs of the participants were continuously measured for 5 consecutive days, starting on Thursday morning and ending on Monday evening, using two wearables devices (a chest patch and a wristband). All participants provided informed consent before participating in the study.

This observational study was approved by the Research Ethical Committee of UZ Leuven (S57916).

\section{Data Collection}

Before the start of the experiment, participants completed an intake questionnaire. The first part inquired about personal information, such as age, gender, health problems, work situation, and lifestyle. Thereafter, four psychological questionnaires were used to assess stress, depression, anxiety, sleep, and general health levels. For this study only perceived chronic stress, measured with the PSS, was considered. The questionnaires were distributed via a dedicated and protected web-based platform. On Thursday morning or afternoon, the participants received and started wearing the two wearable devices, including a chest patch [24] that obtained an electrocardiogram (ECG) at $256 \mathrm{~Hz}$ and a Chillband (wristband) that measured skin conductance at $256 \mathrm{~Hz}$ and skin temperature at $1 \mathrm{~Hz}$. Both devices also measured three-dimensional accelerometer (ACC) signals at $32 \mathrm{~Hz}$ to control for movement artifacts. For this study, only the ECG and ACC data of the wearable positioned on the chest was used and only participants with complete ECG data from Friday 12 AM to Monday 4 PM were included for the analysis. This chest patch has been regulatory approved. Participants were advised to wear the chest patch the entire day and night and were asked to remove the chest patch during vigorous physical activities and to shower with a protective cover, since the chest patch is not waterproof.
The battery life of the sensors exceeded the duration of the experiment. Data were recorded and stored on the devices' internal secure digital cards and uploaded to an internal secure cluster at the end of the experiment. For more details on the entire data collection in the SWEET study, refer to the report by Smets et al [13].

\section{PSS as a Reference for Chronic Stress}

The PSS measures "the degree to which situations in one's life are appraised as stressful" [25] and represents a measure of the global level of perceived stress over the past month. The PSS was designed for use in community samples of individuals with at least a junior high school education. Three versions of the PSS exist (the subscales PSS-14 items, PSS-10 items, and PSS-4 items). Psychometric properties, namely internal consistency reliability, test-retest reliability, and construct validity, of the PSS have been reviewed across studies by Lee et al in 2012 [26], where it was suggested that the subscale PSS-10 should be used to measure perceived stress both in practice and research. Therefore, in this study, the PSS-10 was used.

\section{Data Preprocessing}

\section{Feature Calculation}

Based on the ECG data, the HR was derived. Refer to the study by Smets et al [13] for the methods on the quality indicator and peak detection algorithms. The ACC data were used to calculate the magnitude in the $\mathrm{x}, \mathrm{y}$, and $\mathrm{z}$ directions; the average mean of the $\mathrm{x}, \mathrm{y}$, and $\mathrm{z}$ coordinates; and the average SD of the $\mathrm{x}, \mathrm{y}$, and $z$ coordinates. The absolute differences over time of these three features were summed to retrieve an indicator that was used to identify technical malfunctions. The formulas used to calculate each of the features can be found in Multimedia Appendix 1.

\section{Filtering Methods}

After feature calculation, a data set was obtained with values for the discussed features per minute. First, because all participants started and ended the assessments at different times on Thursday and Monday, the data of Thursday and the data after Monday 4 PM were removed. The data of every participant finally ranged from Friday 12 AM to Monday 4 PM. Second, technical malfunctions (ie, sensor saturation and poor patch adherence) were empirically detected based on the ACC data. For every minute, the indicator retrieved from three ACC features over the 10 closest minutes was calculated. If this value was less than an empirically selected threshold of 0.0005 , the patch was probably either removed from the chest during this period or not measuring correctly. These data points were not included in further analysis. To filter out the values affected by artifacts from the remaining HR, two filters were used. First, the individual's median value \pm 3 times the SD were used as limits. Second, the minimum HR was set to 30 beats per minute, according to previous studies using HR filters [27,28]. The maximum HR was calculated based on the formula reported by Tanaka et al [29] shown in Multimedia Appendix 1. To assess low-frequency changes in HR, all data were summarized per hour. For the weekday against weekend comparison, Friday and Monday were labeled as no, and Saturday and Sunday were labeled as yes for the variable called weekend. Subjects who 
did not have 24 or more hours of data for both a weekday and weekend day were excluded from the analysis. Figure 1 shows

the data extraction, feature calculation, and filtering methods.

Figure 1. Diagram showing all steps from data upload to model development. ACC: accelerometer; AVGM: average mean acceleration of the $x$, $y$, and $\mathrm{z}$ coordinates; AVGSD: average standard deviation in acceleration of the $\mathrm{x}, \mathrm{y}$, and $\mathrm{z}$ coordinates; ECG: electrocardiogram; HR: heart rate; MXYZ: magnitude of acceleration in the $\mathrm{x}, \mathrm{y}$, and $\mathrm{z}$ directions. See Multimedia Appendix 1 for calculation of the features.

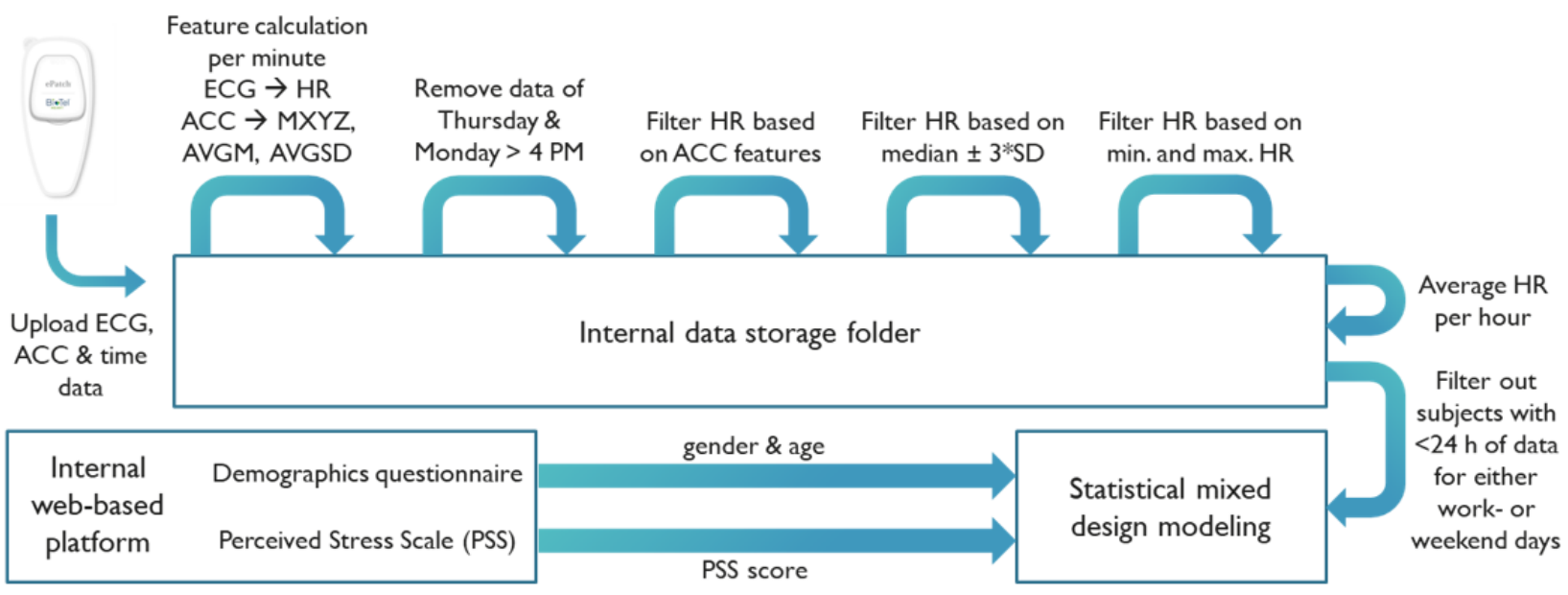

\section{Statistical Analysis}

\section{Model Development}

The retrieved average HR per hour functioned as the outcome of a mixed design model implemented in RStudio using the "Imer" method from the "Ime4" Rpackage. As predictors, the hour of the day, harmonics over time, weekend (yes/no), gender, age, and PSS score were added in the respective order. The subject number was used as a random between-subject intercept and weekend was used as a random within-subject intercept. The time of the day was used in multiple ways based on previous studies on HR over time. First, according to the study by Morelli et al [21], the correlation between HR and time of the day is best described by a four-harmonic fit with periods of $24,12,8$, and 6 hours. Second, Field et al [30] stated that because of the autoregressive property of physiological signals over time, the "corAR1" function is used as a correlational matrix, which includes the correlations within the hour of the day with random intercepts for each participant and workdays versus weekend days. Therefore, random slopes were used both for the hour of the day as a linear continuous variable and for the four harmonics in time that interacted with the weekend because of the differences in the pattern of HR between workdays and weekend days, as reported previously [31]. The method of comparison was set to "ML" (maximum likelihood), which, according to Field et al [30], is the best way to compare multilevel models. In "control," the maximum number of iterations was set to 200 and "returnObject" was set to true to make sure the models are not removed because of optimization issues. Not applicable (NA) values were excluded.

Gender, age, and the PSS score were added as fixed effects separately. All two-way interactions and three-way interactions were included. Interaction effects were included either if they were significant or, for the two-way interaction effects, if the three-way interaction effects with both the main effects were significant. Three-way interactions were only included when all related two-way interactions were included as well. Since the study focused on long-term effects, for the interactions with between-subject variables and time, only interactions with the circadian harmonic (the harmonic over 24 hours) were included. For the interactions between weekend and time, all harmonics were included because the random slopes differed for workdays and weekend days.

\section{Model Comparison}

Initially, the median and interquartile range (IQR) were calculated for the age, PSS score and HR. The HR, age, and PSS score were compared between male and female participants using a Mann-Whitney-Wilcoxon test, while HR on workdays and weekend days was compared using a Wilcoxon signed-rank test. In the final model, we included only interactions that significantly improved the model, which were related to a drop in the Akaike information criterion (AIC) value and an increase in the log likelihood (LogLik) value. The final model was compared to a similar model without the main PSS effect and interaction effects including the PSS score. The comparison was performed using the "Anova" method from the "ImerTest" Rpackage. To analyze the fixed effects and interaction effects, the chi-square test statistic $\left(\chi_{\mathrm{df}}^{2}\right)$ and $P$ value were calculated.

\section{Results}

\section{Population Characteristics}

Table 1 shows the population characteristics for all participants included in the analysis. A total of 328 participants fulfilled the criteria of having complete ECG data from Friday 12 AM to Monday $4 \mathrm{PM}$. There were slightly more male participants $(n=186,56.7 \%)$ than female participants $(n=142,43.3 \%)$ in the analysis. The Mann-Whitney-Wilcoxon test showed that between male and female participants, there were significant differences in the PSS score $\left(\mathrm{W}=1.61 \mathrm{e}^{4}, P<.001\right)$ and the median HR $\left(\mathrm{W}=1.67 \mathrm{e}^{4}, P<.001\right)$, but not in age $\left(\mathrm{W}=1.46 \mathrm{e}^{4}, P=.10\right)$. The Wilcoxon signed-rank test showed that there was a 
Table 1. Descriptive statistics for the population characteristics ( $\mathrm{N}=328)$.

\begin{tabular}{lcc}
\hline Characteristics & Median (IQR) & Comparison test result $^{\mathrm{a}}$ \\
\hline Age (years) & $37.0( \pm 16.8)$ & $\mathrm{W}=1.46 \mathrm{e}^{4}, P=.10$ \\
Male $(\mathrm{n}=186)$ & $39.0( \pm 15.8)$ & \\
Female $(\mathrm{n}=142)$ & $38.0( \pm 17.0)$ & \\
Total $(\mathrm{n}=328)$ & & $\mathrm{W}=1.61 \mathrm{e}^{4}, P<.001$ \\
PSS $^{\mathbf{b}}$ score & $13.0( \pm 9.0)$ & \\
Male $(\mathrm{n}=186)$ & $15.0( \pm 9.0)$ & \\
Female $(\mathrm{n}=142)$ & $14.0( \pm 9.0)$ & \\
Total $(\mathrm{n}=328)$ & & $\mathrm{W}=1.67 \mathrm{e}^{4}, P<.001$ \\
HR $^{\mathbf{c}}$ (bpm $\left.{ }^{\mathbf{d}}\right)$ & $72.5( \pm 12.0)$ & \\
Male $(\mathrm{n}=186)$ & $75.8( \pm 10.0)$ & $\mathrm{V}=2.23 \mathrm{e}^{4}, P=.007$ \\
Female $(\mathrm{n}=142)$ & $73.6( \pm 12.3)$ & \\
Workdays $(\mathrm{n}=328)$ & $73.7( \pm 10.9)$ & \\
Weekend days $(\mathrm{n}=328)$ & $73.5( \pm 10.8)$ & \\
Total $(\mathrm{n}=328)$ & &
\end{tabular}

${ }^{\mathrm{a}}$ For comparing male and female participants, the Mann-Whitney-Wilcoxon test was used. For comparing workdays and weekend days, the Wilcoxon signed-rank test was used.

${ }^{\mathrm{b}}$ PSS: Perceived Stress Scale.

${ }^{\mathrm{c}} \mathrm{HR}$ : heart rate.

$\mathrm{d}_{\text {bpm: beats per minute. }}$

\section{Final Model}

In the final model, 15,699 out of 15,744 observations (99.71\%) were included after exclusion of NA values. The predictors included in the final model (AIC=100379.1, LogLik=-50043.6) were (1) the hour of the day, (2) the circadian harmonic, (3) the 12-hour harmonic, (4) the 8-hour harmonic, and (5) the 6-hour harmonic as time components; (6) whether it was the weekend as a within-subject variable; and (7) gender, (8) the PSS score, and (9) age as between-subject variables.

The two-way interaction effects included the following: whether it was the weekend $x$ every harmonic over time; gender $\times$ 24-hour harmonic; age $\times 24$-hour harmonic; PSS score $\times 24$-hour harmonic; gender $\times$ PSS score; and age $\times$ whether it was the weekend.

The following two three-way interaction effects were included in the final model: gender $\times$ PSS score $\times 24$-hour harmonic; and age $\times$ whether it was the weekend $\times 24$-hour harmonic. The final model, including these predictors, had the lowest AIC value compared with all other models possible with the same main effects. In Multimedia Appendix 2, the built of the final model is shown with AIC and LogLik values for every layer. The final model significantly outperformed the same model without the PSS score and its interactions as predictors (AIC $=100381.0, \operatorname{LogLik}=-50050.51)$, according to an Anova model comparison $\left(\chi_{6}^{2}=13.88, P=.03\right)$.

\section{Random Intercepts and Slopes}

The random intercepts per participant $\left(\chi_{1}^{2}=6948.7, P<.001\right)$ and for workdays and weekend days $\left(\chi_{1}^{2}=233.9, P<.001\right)$ both significantly improved the model. Adding random slopes for the time of the day $\left(\chi_{4}^{2}=391.6, P<.001\right)$; the circadian effect of time $\left(\chi_{14}^{2}=1294.3, P<.001\right)$; and the harmonic over 12 hours $\left(\chi_{22}^{2}=668.7, P<.001\right)$, over 8 hours $\left(\chi_{30}^{2}=148.3, P<.001\right)$, and over 6 hours $\left(\chi_{38}^{2}=361.9, P<.001\right)$ significantly improved the model of HR. Adding an autoregressive correlation of HR over time also significantly improved the model $\left(\chi_{1}^{2}=12097.4\right.$, $P<.001)$.

\section{Main Effects of Time, Weekend, Gender, Age, and PSS Score}

There were significant correlations with the HR for the main effects of the hour of the day $\left(\chi_{1}^{2}=73.22, P<.001\right)$; the circadian harmonic $\left(\chi_{2}^{2}=284.4, P<.001\right)$; the harmonic over 12 hours $\left(\chi_{2}^{2}=242.1, P<.001\right)$, over 8 hours $\left(\chi_{2}^{2}=23.78, P<.001\right)$, and over 6 hours $\left(\chi_{2}^{2}=82.96, P<.001\right)$; and gender $\left(\chi_{1}^{2}=24.02\right.$, $P<.001)$. Table 1 shows a significant difference in HR for gender. However, whether it was a workday or weekend day was not significantly associated with $\mathrm{HR}\left(\chi_{1}^{2}=1.13, P=.29\right)$. The age $\left(\chi_{1}^{2}=0.019, P=.89\right)$ and PSS score $\left(\chi_{1}^{2}=0.42, P=.52\right)$ 
of the participant also did not have a significant correlation with HR.

\section{Two-Way Interaction Effects With Circadian Harmonic Over Time}

There were significant correlations with HR for the interaction effects of weekend and the circadian harmonic $\left(\chi_{2}^{2}=24.98\right.$,
$P<.001)$, weekend and the harmonic over 12 hours $\left(\chi_{2}^{2}=112.5\right.$, $P<.001)$, weekend and the harmonic over 8 hours $\left(\chi_{2}^{2}=94.07\right.$, $P<.001)$, and weekend and the harmonic over 6 hours $\left(\chi_{2}^{2}=131.4, P<.001\right)$. In Figure 2, HR is shown over the time of the day separately for gender and workdays and weekend days.

Figure 2. The heart rate (HR) over the time of the day, split for gender and workdays and weekend days. Since the data are summarized per hour, data points are provided in the middle of the hours. The error bars represent the $95 \%$ confidence intervals.

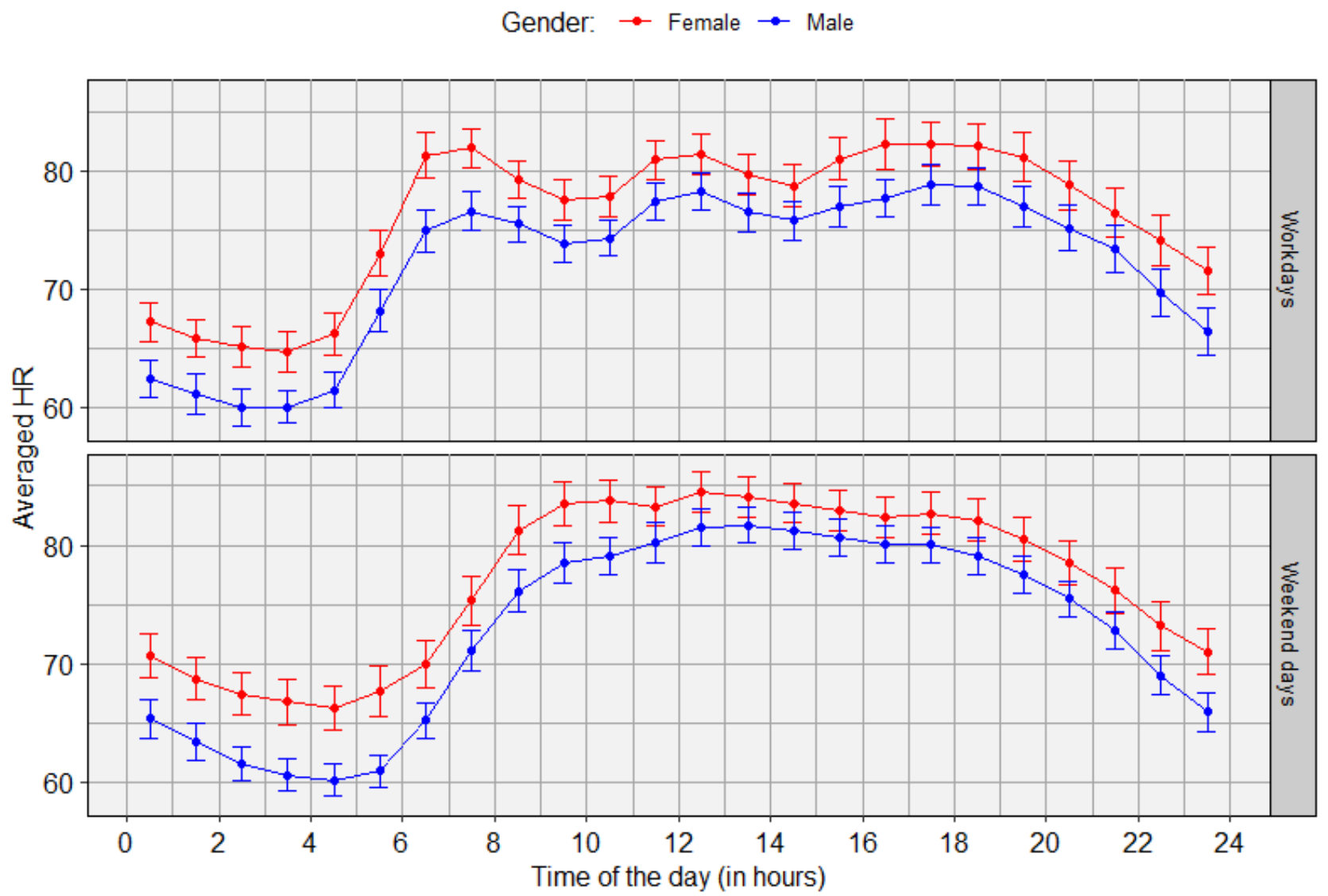

Furthermore, a significant correlation with HR was found for the interaction effect between gender and the circadian harmonic $\left(\chi_{2}^{2}=17.01, P<.001\right)$ and between age and the circadian harmonic $\left(\chi_{2}^{2}=16.69, P<.001\right)$. Although the interaction effect between the PSS score and the circadian harmonic was not significantly correlated with $\operatorname{HR}\left(\chi_{2}^{2}=2.62, P=.27\right)$, it was included in the final model because of a significant higher order interaction effect.

\section{Two-Way Interaction Effect Between Age and Weekend, and Between Gender and the PSS Score}

The correlation between HR and the interaction effect of gender and the PSS score of the participant was slightly nonsignificant $\left(\chi_{1}^{2}=3.63, P=.06\right)$. It was still included in the model, because of a significant higher order interaction effect. Although there was no significant correlation with HR for the interaction effect between age and whether it was the weekend $\left(\chi_{1}^{2}=0.34, P=.56\right)$, the interaction effect was included in the final model, because of a higher order interaction effect.

\section{Three-Way Interaction Effect Among Age, Weekend, and Circadian Harmonic}

There was a significant correlation between $\mathrm{HR}$ and the three-way interaction effect among age, whether it was a workday or weekend day, and the circadian harmonic $\left(\chi_{2}^{2}=7.13\right.$, $P=.03)$. Figure 3 shows the effect of age on HR for every hour of the day, split for workdays and weekend days. On workdays, the correlation between age and HR switched from positive to negative at around 7 AM, whereas on weekend days, the same correlation switched from positive to negative at around $3 \mathrm{PM}$. 
Figure 3. The heart rate (HR) over age per hour of the day, split for workdays and weekend days. Since the data are summarized per hour, the labels provided are the start of the hour.

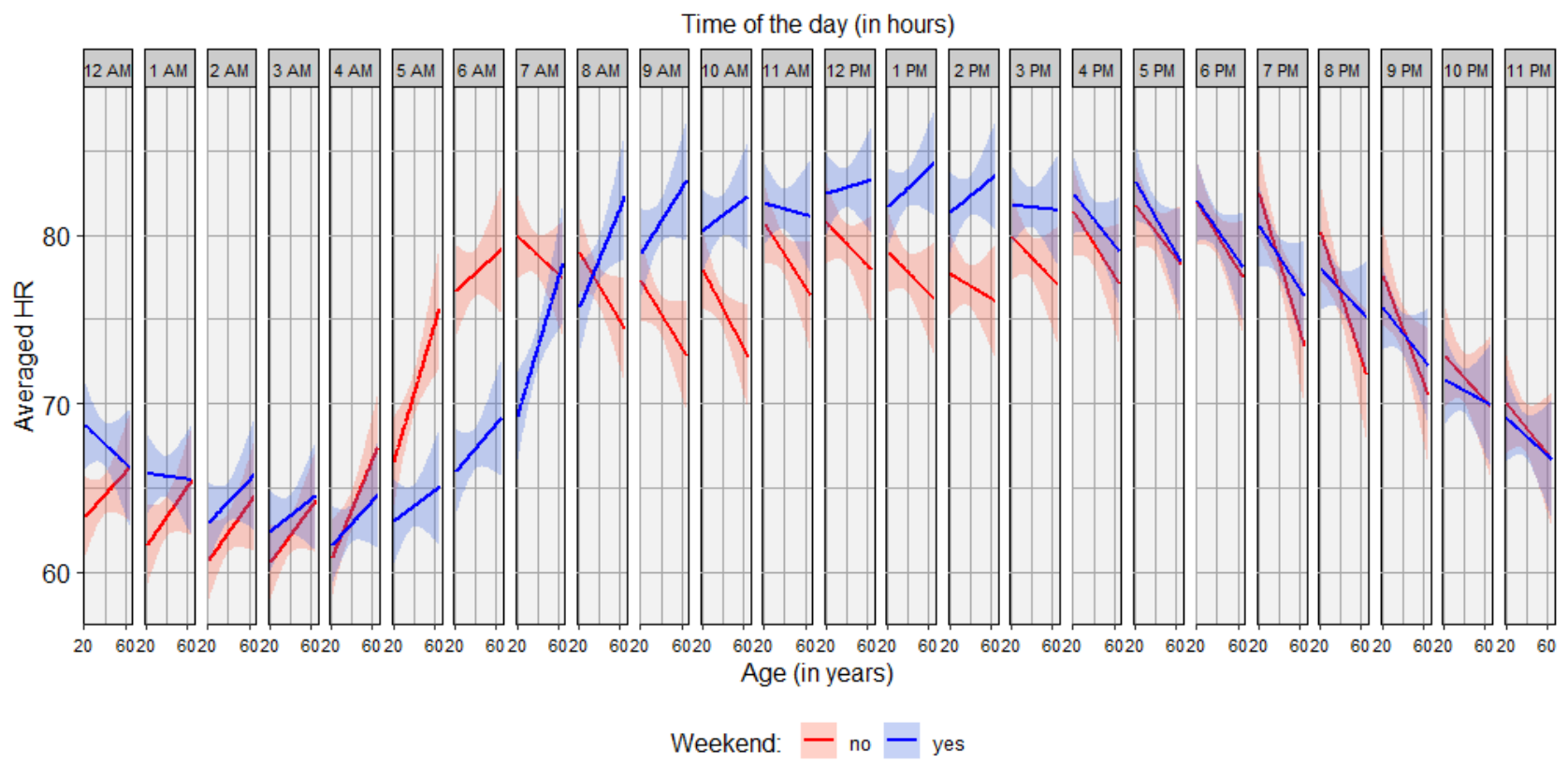

\section{Three-Way Interaction Effect Among Gender, PSS Score, and Circadian Harmonic}

The three-way interaction among gender, the PSS score, and the circadian harmonic was found to be significantly associated with HR $\left(\chi_{2}^{2}=7.59, P=.02\right)$. Figure 4 shows the effect of the PSS score on HR for every hour of the day, split for female and male participants. The positive correlation between the PSS score and HR for male participants was the strongest at around $11 \mathrm{AM}$ and flattened in the night. The negative correlation between the PSS score and HR for female participants was the strongest in the night/early morning and flattened or even switched to a slightly positive correlation at around 6 PM to 8 PM.

Figure 4. The heart rate (HR) over the Perceived Stress Scale (PSS) score for every hour of the day, split for female and male participants. The time above each subsection provides the starting time of the hour for which the HR is shown.

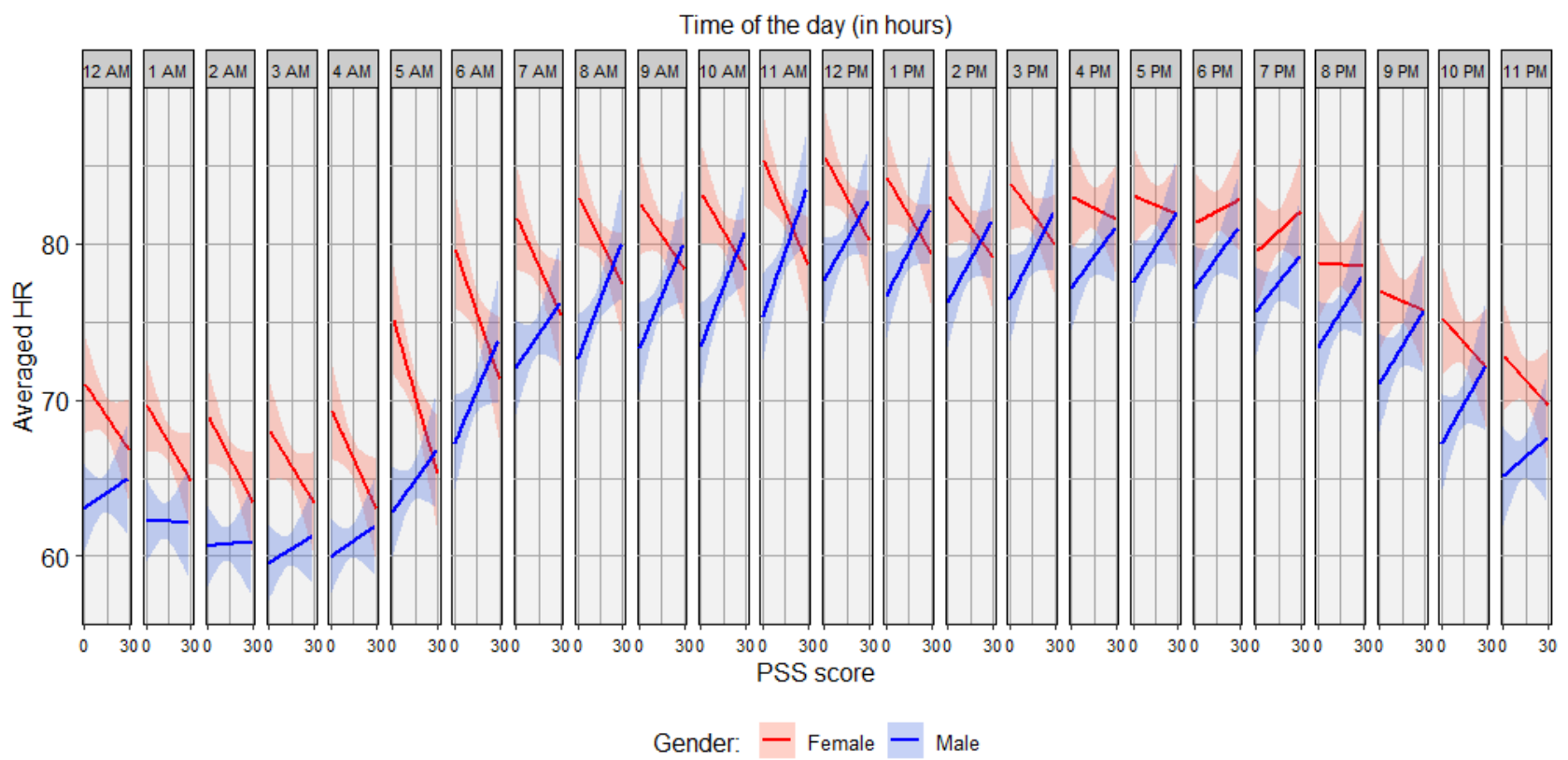

\section{Discussion}

\section{Principal Findings}

In this observational study, the circadian rhythm was defined as a combination of the 24-hour harmonic, 12-hour harmonic, 8-hour harmonic, and 6-hour harmonic, which were all found to be predictors of HR over time. The median HR was found to be different for male and female participants and for weekdays versus weekends. A relationship between HR and the three-way interaction of age, the circadian harmonic, and whether it was the weekend was found. Moreover, HR was 
found to be related to the three-way interaction of the PSS score, gender, and the circadian harmonic.

The results confirm the validity of a four-harmonic circadian rhythm in HR as described by Morelli et al [21]. This is shown by the random slopes in harmonics over $24,12,8$, and 6 hours and by the main effects of the four harmonics. However, four-harmonic circadian HR fluctuations were different between workdays and weekend days, as shown in Figure 2. Moreover, the random intercept for weekends and the difference in HR between workdays and weekend days, as shown in Table 1, suggested a different average HR for workdays and weekend days. The fact that there was no main effect of weekend is likely related to the inclusion of weekend as a random intercept. These findings match the findings of Cavallari et al [31] and suggest that specific HR models for workdays and weekend days are needed. Jones et al [17] related circadian HR fluctuations to circadian cortisol fluctuations. An increase in cortisol gives rise to appetite, resulting in food intake and therefore an increase in energy and HR. After eating, the parasympathetic nervous system is activated, which stimulates the gastrointestinal tract for food processing [32]. This activation is accompanied by a decrease in HR [33]. Figure 2 shows that for workdays, the eating times were very similar for everyone, with breakfast between $6 \mathrm{AM}$ and $8 \mathrm{AM}$, lunch between $11 \mathrm{AM}$ and $2 \mathrm{PM}$, and dinner between 5 PM and 8 PM. On weekends, the eating times are likely to be less congruent among participants, resulting in a smoothened average over the day. The study population consisted of office workers. All working people follow a very similar work rhythm (go to work, sit at work, have lunch, sit at work, and go home at roughly similar times), whereas on weekends, there is much more variability among people. It needs to be verified how this difference between workdays and weekend days scales to a different kind of working population, for example, shift workers having different daily patterns. Another clear difference in HR between workdays and weekend days was the timing of the HR morning awakening response. For workdays, HR rises earlier than for weekend days, which could be related to the earlier awakening times on workdays [34].

The average HR as well as the four-harmonic circadian HR fluctuations were different for not only workdays and weekend days but also participants, as indicated by the random intercept and slopes per participant. This suggests a need for personalized circadian HR models, which has been discussed previously by Fijorek et al [35]. This personalization is also suggested based on the higher average HR for female participants, as shown in Table 1, and the difference between male and female participants in circadian fluctuations in HR, as shown in Figure 2. According to Sandstede et al [36], the higher average HR for female participants is related to their average lower cardiac mass. Figure 2 shows that at daytime, the HRs of male and female participants are closer to each other than at night, which was also observed by Fijorek et al [35] and Bonnemeier et al [37]. According to Gregoire et al [38], the lower day-night difference for female individuals is probably related to the lower activity of the sympathetic nervous system in women, especially during the daytime.
Since the maximum HR decreases linearly with age [29], a correlation between age and HR might have been expected as well. However, this effect was not found to be relevant. This could be related to participant inclusion as a random intercept, explaining a part of the variance caused by differences in age. Nevertheless, age interacts with the circadian rhythm in HR differently for workdays and weekend days, as shown in Figure 3. There was a decrease in amplitude of HR fluctuations with age for workdays but not for weekend days. Hood \& Shimon [39] have published a review on the aging clock and its circadian rhythms, in which they describe a lower amplitude of both cortisol and waking activity fluctuations, resulting in similar lower amplitudes of circadian HR fluctuations, described as flattening of the sinusoidal curve, as age increases. This explains the positive correlation between age and HR until 7 AM for workdays, which turns negative and then turns positive again around 12 AM, as can be seen in Figure 3. A higher nocturnal nadir of cortisol levels for higher ages was found by Van Cauter et al [40] and Sharma et al [41]. The translation of cortisol levels to long-term HR levels was not made in these studies but is used more often in stress studies $[17,42]$. On weekends, the positive correlation between age and HR turned negative at around $3 \mathrm{PM}$ and then positive again at around $2 \mathrm{AM}$. The shift of the switch from negative to positive from $12 \mathrm{AM}$ on workdays to $2 \mathrm{AM}$ on weekend days could be related to later sleeping times during the weekend [43]. In general, it seems that the average HR during work nights (12 AM to 4 AM) is slightly lower than that during weekend nights, because people go to sleep later during the weekend. However, this does not explain why the switch from a positive correlation of age and HR to a negative correlation shifted from $7 \mathrm{AM}$ on workdays to $3 \mathrm{PM}$ on weekend days. Between 7 AM and 3 PM, there might be the most variance in activity among participants, since these are free hours during weekend days and work hours during workdays. Activity trackers could provide more understanding on the different directions of the correlation between age and HR for workdays and weekend days.

Lastly, no correlations between HR and the main effect of the PSS or HR and the two-way interaction effects of the PSS and other predictors were found. However, a correlation was found between HR and the three-way interaction of gender, the PSS score, and the circadian harmonic. This suggests that the effect of chronic stress can only be captured by including the dynamics of HR over time. Figure 4 shows that the correlation of the PSS and HR was exactly opposite for male and female participants throughout the day, except for the periods around 1 AM to 3 $\mathrm{AM}$ and $6 \mathrm{PM}$ to $8 \mathrm{PM}$. In the first period, a flattening of the positive correlation between the PSS score and HR was noted for male participants, while in the second period, the negative correlation between the PSS score and HR for female participants switched to a slightly positive correlation. Table 1 shows that beside the difference in HR between male and female participants, there was a difference in the PSS score, which was found by Remor [6]. However, this does not explain the more complex three-way interaction effect including circadian fluctuations. Jones et al [17] described similar results, as seen in Figure 4, only for acute stress responses and explained it as a gender difference in evolution-based energy utilization strategies. Male individuals have a well-studied stress response, 
often called the fight-or-flight response [44,45]. However, for female individuals, Taylor et al [46] introduced a different response, called the tend-or-befriend response. For long-term stress, the fight-or-flight response means stacking up resources to increase energy that might be needed for an actual fight-or-flight situation. In terms of biology, this means an increase in cortisol, accompanied by an increase in appetite, which results in an increase in food intake and energy, resulting in an increased HR [17]. This male-specific chronic stress response could be related to the correlation of job strain and obesity in male individuals but not female individuals, which was found by Brunner et al [47]. The tend-or-befriend response in female individuals would stimulate nurturing and caring behaviors, making sure that, for example, their children have enough resources [46]. This is related to a decrease in food intake, causing the depletion of fat stores and a decrease in HR among female individuals [17]. In the literature, this female evolutionary behavior has also been described as the biological reason why female individuals have, in general, higher fat storage than male individuals [48]. The theory explains the positive correlation between the PSS and HR for male participants and the negative correlation between the PSS and HR for female participants. In Figure 4, the period from 6 PM to 8 PM, when the correlation between the PSS and HR switched from negative to positive for female participants, could be explained by dinner time, which includes food intake among female individuals as well. The period from $1 \mathrm{AM}$ to $3 \mathrm{AM}$, when the positive correlation between the PSS score and HR for male participants flattened, can be explained by the absence of food intake at night and no increased HR associated with chronic stress during that period. This theory should be studied in more detail in relation to circadian HR, comparing the circadian physiology of male and female individuals for different stress levels and linking HR to cortisol, sleep, and mealtime as well.

\section{Limitations}

This study only involved two workdays (Monday and Friday) and two weekend days (Saturday and Sunday) per participant. For the workdays, Monday stopped at 4 PM. The effect of this limitation can easily be seen in Figure 4, where the CIs in the plots seem to increase from 4 PM. It would be interesting to include more workdays and weekend days of multiple weeks, so an average over multiple days could provide a more consistent long-term measurement of HR fluctuations.

\section{Future Work}

The autonomic stress response includes several physiological changes, of which we investigated the HR response. Our longitudinal analysis should be applied to other physiological signals, such as skin temperature, galvanic skin response, and blood pressure $[5,13,14]$. These physiological measurements are known to have circadian fluctuations as well. It is also recommended to include longitudinal cortisol measurements to better understand the interaction across individual characteristics, hormonal mechanisms, and physiology in chronic stress. Information on sport activities, food intake times, and sleep times could also be considered to provide more context regarding physiological changes.

\section{Conclusions}

This study confirmed previous findings on the circadian rhythm of HR, its difference between workdays and weekend days, and its interactions with gender and age. The main discovery is the relationship between $\mathrm{HR}$ and the three-way interaction of chronic stress, gender, and the circadian harmonic. Our findings suggest that chronic stress prediction models and objective chronic stress measurements based on continuous HR detection should include interaction effects with circadian harmonics and gender to explain more subject variability. The development of these prediction models would enable continuous monitoring of long-term stress levels that could support therapists and psychologists to better understand patient progress and well-being.

\section{Acknowledgments}

This work was supported by a PhD fellowship from the Research Foundation-Flanders (FWO) awarded to EL (1SB4719N). Furthermore, we would like to thank Emmanuel Rios Velazquez and Vojkan Mihajlovic for carefully reviewing our manuscript.

OnePlanet Research Center acknowledges the support of the Province of Gelderland.

\section{Authors' Contributions}

Conceptualization: AK, GS, and EL; data curation: GS; formal analysis: AK, GS, and EL; investigation: AK, GS, and EL; methodology: AK, GS, and EL; project administration: AK and GS; resources: $\mathrm{CH}$; supervision: $\mathrm{GS}$ and $\mathrm{CH}$; visualization: $\mathrm{AK}$ and GS; writing-original draft preparation: $\mathrm{AK}$ and GS; writing-review and editing: $\mathrm{AK}, \mathrm{GS}$, EL, SC, and $\mathrm{CH}$; guarantor: $\mathrm{CH}$.

\section{Conflicts of Interest}

None declared.

\section{Multimedia Appendix 1}

Formulas.

[DOCX File , 20 KB-Multimedia Appendix 1] 


\section{Multimedia Appendix 2}

Models.

[DOCX File, 23 KB-Multimedia Appendix 2]

\section{References}

1. Mojtabai R, Olfson M, Han B. National Trends in the Prevalence and Treatment of Depression in Adolescents and Young Adults. Pediatrics 2016 Dec;138(6) [FREE Full text] [doi: 10.1542/peds.2016-1878] [Medline: 27940701]

2. Yaribeygi H, Panahi Y, Sahraei H, Johnston T, Sahebkar A. The impact of stress on body function: A review. EXCLI J 2017;16:1057-1072 [FREE Full text] [doi: 10.17179/excli2017-480] [Medline: 28900385]

3. McGonagle K, Kessler R. Chronic stress, acute stress, and depressive symptoms. Am J Community Psychol 1990 Oct;18(5):681-706. [doi: 10.1007/BF00931237] [Medline: 2075897]

4. Hassard J, Teoh KR, Visockaite G, Dewe P, Cox T. The cost of work-related stress to society: A systematic review. J Occup Health Psychol 2018 Jan;23(1):1-17. [doi: 10.1037/ocp0000069] [Medline: 28358567]

5. Kaplan H. Psychosocial stress: Perspectives on structure, theory, life-course, and methods. San Diego: Academic Press; 1996.

6. Remor E. Psychometric properties of a European Spanish version of the Perceived Stress Scale (PSS). Span J Psychol 2006 May;9(1):86-93. [doi: 10.1017/s1138741600006004] [Medline: 16673626 ]

7. Lesage F, Berjot S, Deschamps F. Psychometric properties of the French versions of the Perceived Stress Scale. Int J Occup Med Environ Health 2012 Jun;25(2):178-184 [FREE Full text] [doi: 10.2478/S13382-012-0024-8] [Medline: 22528542]

8. Ramírez MT, Hernández RL. Factor structure of the Perceived Stress Scale (PSS) in a sample from Mexico. Span J Psychol 2007 May;10(1):199-206. [doi: 10.1017/s1138741600006466] [Medline: 17549893]

9. Taylor JM. Psychometric analysis of the Ten-Item Perceived Stress Scale. Psychol Assess 2015 Mar;27(1):90-101. [doi: 10.1037/a0038100] [Medline: 25346996]

10. Can YS, Arnrich B, Ersoy C. Stress detection in daily life scenarios using smart phones and wearable sensors: A survey. J Biomed Inform 2019 Apr;92:103139 [FREE Full text] [doi: 10.1016/j.jbi.2019.103139] [Medline: 30825538]

11. Castaldo R, Montesinos L, Melillo P, Massaro S, Pecchia L. To What Extent Can We Shorten HRV Analysis in Wearable Sensing? A Case Study on Mental Stress Detection. In: Eskola H, Väisänen O, Viik J, Hyttinen J, editors. EMBEC \& NBC 2017, IFMBE Proceedings. Singapore: Springer; 2018:643-646.

12. Boonnithi S, Phongsuphap S. Comparison of heart rate variability measures for mental stress detection. 2011 Presented at: Computing in Cardiology; September 18-21, 2011; Hangzhou, China.

13. Smets E, Rios Velazquez E, Schiavone G, Chakroun I, D'Hondt E, De Raedt W, et al. Large-scale wearable data reveal digital phenotypes for daily-life stress detection. NPJ Digit Med 2018;1:67 [FREE Full text] [doi: 10.1038/s41746-018-0074-9] [Medline: 31304344$]$

14. Yu H, Klerman E, Picard R, Sano A. Personalized wellbeing prediction using behavioral, physiologicalweather data. 2019 Presented at: International Conference on Biomedical \& Health Informatics (BHI); May 2019; Chicago, USA. [doi: 10.1109/bhi.2019.8834456]

15. Van Uum SH, Sauvé B, Fraser LA, Morley-Forster P, Paul TL, Koren G. Elevated content of cortisol in hair of patients with severe chronic pain: a novel biomarker for stress. Stress 2008 Nov;11(6):483-488. [doi: 10.1080/10253890801887388] [Medline: 18609301$]$

16. Schulz P, Kirschbaum C, Prüßner J, Hellhammer D. Increased free cortisol secretion after awakening in chronically stressed individuals due to work overload. Stress Med 1998 Apr;14(2):91-97 [FREE Full text] [doi:

10.1002/(sici)1099-1700(199804)14:2<91::aid-smi765>3.0.co;2-s]

17. Jones A, Pruessner JC, McMillan MR, Jones RW, Kowalik GT, Steeden JA, et al. Physiological adaptations to chronic stress in healthy humans - why might the sexes have evolved different energy utilisation strategies? J Physiol 2016 Aug 01;594(15):4297-4307 [FREE Full text] [doi: 10.1113/JP272021] [Medline: 27027401]

18. Cornelissen G. Cosinor-based rhythmometry. Theor Biol Med Model 2014 Apr 11;11:16 [FREE Full text] [doi: 10.1186/1742-4682-11-16] [Medline: 24725531]

19. Cho C, Lee T, Kim M, In HP, Kim L, Lee H. Mood Prediction of Patients With Mood Disorders by Machine Learning Using Passive Digital Phenotypes Based on the Circadian Rhythm: Prospective Observational Cohort Study. J Med Internet Res 2019 Apr 17;21(4):e11029 [FREE Full text] [doi: 10.2196/11029]

20. Tsanas A, Woodward E, Ehlers A. Objective Characterization of Activity, Sleep, and Circadian Rhythm Patterns Using a Wrist-Worn Actigraphy Sensor: Insights Into Posttraumatic Stress Disorder. JMIR Mhealth Uhealth 2020 Apr 20;8(4):e14306 [FREE Full text] [doi: 10.2196/14306] [Medline: 32310142]

21. Morelli D, Bartoloni L, Rossi A, Clifton DA. A computationally efficient algorithm to obtain an accurate and interpretable model of the effect of circadian rhythm on resting heart rate. Physiol Meas 2019 Sep 30;40(9):095001. [doi: 10.1088/1361-6579/ab3dea] [Medline: $\underline{\text { 31437825] }}$ 
22. Schlotz W, Hellhammer J, Schulz P, Stone AA. Perceived work overload and chronic worrying predict weekend-weekday differences in the cortisol awakening response. Psychosom Med 2004;66(2):207-214. [doi: 10.1097/01.psy.0000116715.78238.56] [Medline: 15039505$]$

23. Pantzar M, Ruckenstein M, Mustonen V. Social rhythms of the heart. Health Sociol Rev 2017 Jan 02;26(1):22-37 [FREE Full text] [doi: 10.1080/14461242.2016.1184580] [Medline: 28163655]

24. ePatch extended holter monitoring. BioTelemetry Inc. URL: https://www.gobio.com/heart-monitoring/14dayepatch/ [accessed 2020-06-05]

25. Cohen S, Kamarck T, Mermelstein R. A Global Measure of Perceived Stress. Journal of Health and Social Behavior 1983 Dec;24(4):385-396 [FREE Full text] [doi: 10.2307/2136404]

26. Lee E. Review of the psychometric evidence of the perceived stress scale. Asian Nurs Res (Korean Soc Nurs Sci) 2012 Dec;6(4):121-127 [FREE Full text] [doi: 10.1016/j.anr.2012.08.004] [Medline: 25031113]

27. Kostis JB, Moreyra AE, Amendo MT, Di Pietro J, Cosgrove N, Kuo PT. The effect of age on heart rate in subjects free of heart disease. Studies by ambulatory electrocardiography and maximal exercise stress test. Circulation 1982 Jan;65(1):141-145. [doi: 10.1161/01.cir.65.1.141] [Medline: 7198013]

28. Orphanidou C, Bonnici T, Charlton P, Clifton D, Vallance D, Tarassenko L. Signal-quality indices for the electrocardiogram and photoplethysmogram: derivation and applications to wireless monitoring. IEEE J Biomed Health Inform 2015 May;19(3):832-838. [doi: 10.1109/JBHI.2014.2338351] [Medline: 25069129]

29. Tanaka H, Monahan KD, Seals DR. Age-predicted maximal heart rate revisited. Journal of the American College of Cardiology 2001 Jan;37(1):153-156 [FREE Full text] [doi: 10.1016/s0735-1097(00)01054-8]

30. Field A, Miles J, Field Z. Discovering Statistics Using R. London: Sage Publications; 2012.

31. Cavallari JM, Fang SC, Mittleman MA, Christiani DC. Circadian variation of heart rate variability among welders. Occup Environ Med 2010 Oct;67(10):717-719 [FREE Full text] [doi: 10.1136/oem.2010.055210] [Medline: 20798005]

32. D'Alessio DA. Activation of the Parasympathetic Nervous System Is Necessary for Normal Meal-Induced Insulin Secretion in Rhesus Macaques. Journal of Clinical Endocrinology \& Metabolism 2001 Mar 01;86(3):1253-1259 [FREE Full text] [doi: $10.1210 /$ jc. 86.3 .1253 ]

33. Glick G, Braunwald E, Lewis RM. Relative Roles of the Sympathetic and Parasympathetic Nervous Systems in the Reflex Control of Heart Rate. Circulation Research 1965 Apr;16(4):363-375 [FREE Full text] [doi: 10.1161/01.res.16.4.363]

34. Robbins R, Affouf M, Seixas A, Beaugris L, Avirappattu G, Jean-Louis G. Four-Year Trends in Sleep Duration and Quality: A Longitudinal Study Using Data from a Commercially Available Sleep Tracker. J Med Internet Res 2020 Feb 20;22(2):e14735 [FREE Full text] [doi: 10.2196/14735] [Medline: 32078573]

35. Fijorek K, Patel N, Klima ?, Stolarz-Skrzypek K, Kawecka-Jaszcz K, Polak S. Age and gender dependent heart rate circadian model development and performance verification on the proarrhythmic drug case study. Theor Biol Med Model 2013 Feb 09;10:7 [FREE Full text] [doi: 10.1186/1742-4682-10-7] [Medline: 23394137]

36. Sandstede J, Lipke C, Beer M, Hofmann S, Pabst T, Kenn W, et al. Age- and gender-specific differences in left and right ventricular cardiac function and mass determined by cine magnetic resonance imaging. Eur Radiol 2000;10(3):438-442. [doi: 10.1007/s003300050072] [Medline: 10756992]

37. Bonnemeier H, Richardt G, Potratz J, Wiegand UK, Brandes A, Kluge N, et al. Circadian profile of cardiac autonomic nervous modulation in healthy subjects: differing effects of aging and gender on heart rate variability. J Cardiovasc Electrophysiol 2003 Aug;14(8):791-799. [doi: 10.1046/j.1540-8167.2003.03078.x] [Medline: 12890036]

38. Gregoire J, Tuck S, Yamamoto Y, Hughson RL. Heart rate variability at rest and exercise: influence of age, gender, and physical training. Can J Appl Physiol 1996 Dec;21(6):455-470. [doi: 10.1139/h96-040] [Medline: $\underline{8959312]}$

39. Hood S, Amir S. The aging clock: circadian rhythms and later life. J Clin Invest 2017 Feb 01;127(2):437-446 [FREE Full text] [doi: 10.1172/JCI90328] [Medline: 28145903]

40. Van Cauter E, Leproult R, Kupfer DJ. Effects of gender and age on the levels and circadian rhythmicity of plasma cortisol. J Clin Endocrinol Metab 1996 Jul;81(7):2468-2473. [doi: 10.1210/jcem.81.7.8675562] [Medline: $\underline{8675562]}$

41. Sharma M, Palacios-Bois J, Schwartz G, Iskandar H, Thakur M, Quirion R, et al. Circadian rhythms of melatonin and cortisol in aging. Biol Psychiatry 1989 Feb 01;25(3):305-319. [doi: 10.1016/0006-3223(89)90178-9] [Medline: 2914154]

42. Kudielka BM, Schommer NC, Hellhammer DH, Kirschbaum C. Acute HPA axis responses, heart rate, and mood changes to psychosocial stress (TSST) in humans at different times of day. Psychoneuroendocrinology 2004 Sep;29(8):983-992. [doi: 10.1016/j.psyneuen.2003.08.009] [Medline: $\underline{15219648]}$

43. Gubin DG, Weinert D, Rybina SV, Danilova LA, Solovieva SV, Durov AM, et al. Activity, sleep and ambient light have a different impact on circadian blood pressure, heart rate and body temperature rhythms. Chronobiol Int 2017;34(5):632-649. [doi: 10.1080/07420528.2017.1288632] [Medline: 28276854]

44. Collu R, Gibb W, Ducharme JR. Effects of stress on the gonadal function. J Endocrinol Invest 2014 Apr 4;7(5):529-537 [FREE Full text] [doi: 10.1007/bf03348463]

45. Lee J, Harley VR. The male fight-flight response: A result of SRY regulation of catecholamines? Bioessays 2012 Mar 08;34(6):454-457 [FREE Full text] [doi: 10.1002/bies.201100159] 
46. Taylor SE, Klein LC, Lewis BP, Gruenewald TL, Gurung RA, Updegraff JA. Biobehavioral responses to stress in females: tend-and-befriend, not fight-or-flight. Psychol Rev 2000 Jul;107(3):411-429. [doi: 10.1037/0033-295x.107.3.411] [Medline: $\underline{10941275]}$

47. Brunner EJ, Chandola T, Marmot MG. Prospective effect of job strain on general and central obesity in the Whitehall II Study. Am J Epidemiol 2007 Apr 01;165(7):828-837. [doi: 10.1093/aje/kwk058] [Medline: 17244635]

48. Vague J. The degree of masculine differentiation of obesities: a factor determining predisposition to diabetes, atherosclerosis, gout, and uric calculous disease. Am J Clin Nutr 1956;4(1):20-34. [doi: 10.1093/ajcn/4.1.20] [Medline: 13282851]

\section{Abbreviations}

ACC: accelerometer

AIC: Akaike information criterion

ECG: electrocardiogram

HR: heart rate

LogLik: $\log$ likelihood

NA: not applicable

PSS: Perceived Stress Scale

SWEET: Stress in Work Environment

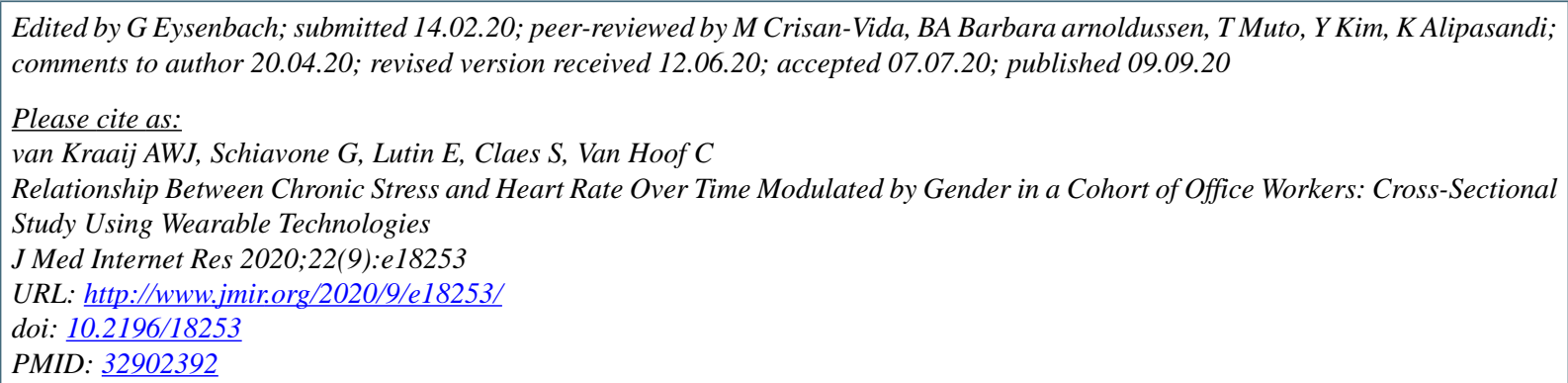

(C)Alex Wilhelmus Jacobus van Kraaij, Giuseppina Schiavone, Erika Lutin, Stephan Claes, Chris Van Hoof. Originally published in the Journal of Medical Internet Research (http://www.jmir.org), 09.09.2020. This is an open-access article distributed under the terms of the Creative Commons Attribution License (https://creativecommons.org/licenses/by/4.0/), which permits unrestricted use, distribution, and reproduction in any medium, provided the original work, first published in the Journal of Medical Internet Research, is properly cited. The complete bibliographic information, a link to the original publication on http://www.jmir.org/, as well as this copyright and license information must be included. 